\title{
Atmospheric Temperature Variation and its Causes in Summer of Jinan for 2015
}

\author{
Baohua Zhou ${ }^{1, a^{*}}$, Zhanhong Liu, ${ }^{1, b}$ and Dong Yuan ${ }^{1, c}$ \\ ${ }^{1}$ Resources and Environmental Institute, University of Jinan, Jinan, China, 250022

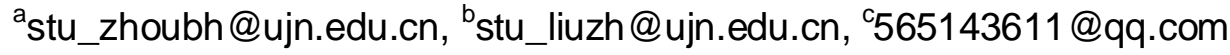 \\ *The corresponding author
}

Keywords: Jinan; Temperature variation; Summer; Urban tropical island effect; El Nino

\begin{abstract}
This paper analyzed spatiotemporal inhomogeneity characteristics and its causes of air temperature based on the observation data of air temperature on June, July, and August in 2015, combined with the geographic information data of Jinan. Research results show the highest average temperature is on July, no extreme temperature, and the spatiotemporal inhomogeneity characteristics of air temperature are similar to other research that is not the effect of El Nino on Jinan in the summer of 2015. The air temperature of the urban district is slightly higher than other suburban areas on July and June in Jinan, but the spatial inhomogeneity of air temperature is not big on August in Jinan. The urban district of Jinan is the highest average temperature throughout the summer of 2015 that is a sign of the urban tropical island effect.
\end{abstract}

\section{Introduction}

Air temperature as an important part of the natural environment in which human beings live, any change of it will have a profound impact on natural ecosystems and socio-economic systems[1]. Review of the literature revealed the former research almost based on the temperature of many years. For example, Hu Guifang, taking Jinan and Qingdao as examples, pointed out that the temperature change of Shandong in recent centuries is similar to the national average[2]. Since 1980s, the most obvious upward trend of this century has appeared. Sun Xian and other research found that the temperature warming trend is not the same in North China in the past 50 years[3]. Zhou Xin used the observation station of the national meteorological data in 1960-2010 and used correlation analysis, filtering, wavelet analysis and other analysis methods to study the interannual and interdecadal characteristics of temporal and spatial variation of air temperature in China and seven climate zones[4]. On the basis of the data of the summer in Ji'nan, the reason for the change of temperature is less. According to the comprehensive evaluation of the National Climate Center, there were 1 super El Nino event in 2014-2016. Its life history, the cumulative length intensity and peak strength have reached the highest since twentieth Century, as observed the strongest El Nino events [5].

In this paper, the temporal and spatial variation characteristics of summer air temperature in Ji'nan are studied by using the summer temperature data of Jinan in June, July and August, 2015. And compared with Gao Weidong's research in summer air temperature changes of Jinan in 1961-2000 and Hu Gang's research in summer air temperature changes of Jinan in 1951-2007[6-7]. In order to provide a basis for further study on the influence of El Nino on the summer temperature of Jinan of June, July and August in 2015.

\section{The temporal inhomogeneity of air temperature}

The data cited is from the Shandong Provincial Meteorological Bureau records, including June 1st to August 31st, 2015, a total of 92 days of maximum temperature, minimum temperature, and the daily average temperature of 276 data in Jinan as well as daily weather conditions, wind direction and other information in Jinan. The data is basically all valid and a small amount of 
invalid data make differential complement according to the data of previous years. In order to explain temporal variation of summer air temperature in Jinan in 2015, this paper analyzes the data from June, July and August firstly, and then analyzes the general trend of three months.

The Temporal Inhomogeneity of Air Temperature in June. Fig. 1 is the temperature change trend chart of Jinan in June, 2015. This paper observes the change of temperature in June from the three periods of early, middle and late.

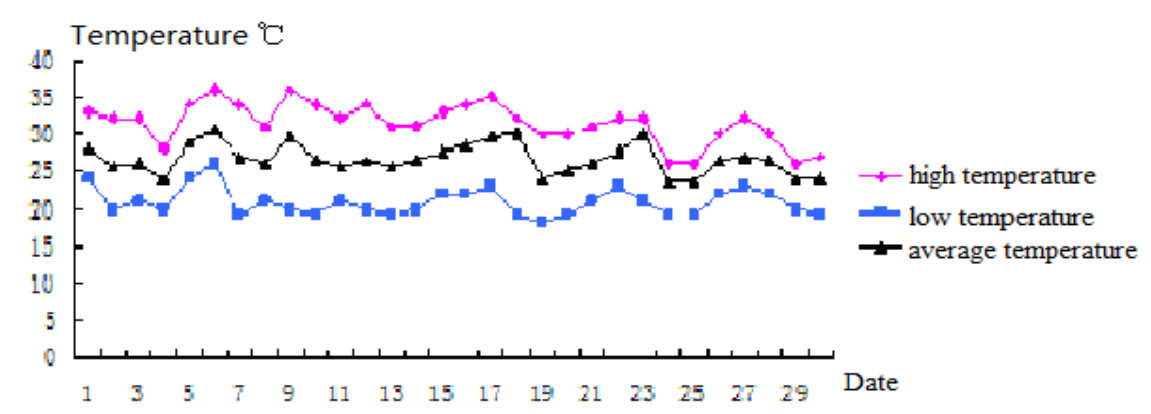

Figure 1. The temperature change of Jinan in June

The high and low temperature in Jinan ranged from $18^{\circ} \mathrm{C}$ to $36^{\circ} \mathrm{C}$.Daily average temperature ranged from $23.5^{\circ} \mathrm{C}$ to $30.5^{\circ} \mathrm{C}$ and the average daily temperature difference was $7{ }^{\circ} \mathrm{C}$. The overall temperature showed a downward trend. The high temperature of the 6 th and 9 th reached the highest temperature of $36^{\circ} \mathrm{C}$ in this month. The Low temperature of the 19th of this month reached the lowest temperature of $18^{\circ} \mathrm{C}$. The temperature in the early part of this month was the highest, daily temperature ranging from $24^{\circ} \mathrm{C}$ to $30.5^{\circ} \mathrm{C}$. Midday average daily temperature ranged from $24^{\circ} \mathrm{C}$ to $30^{\circ} \mathrm{C}$. Late average daily temperature ranged from $23.5^{\circ} \mathrm{C}$ to $30^{\circ} \mathrm{C}$.

The Temporal Inhomogeneity of Air Temperature in July. According to Fig. 2, this paper observes the change of temperature in July from the three periods of early, middle and late.

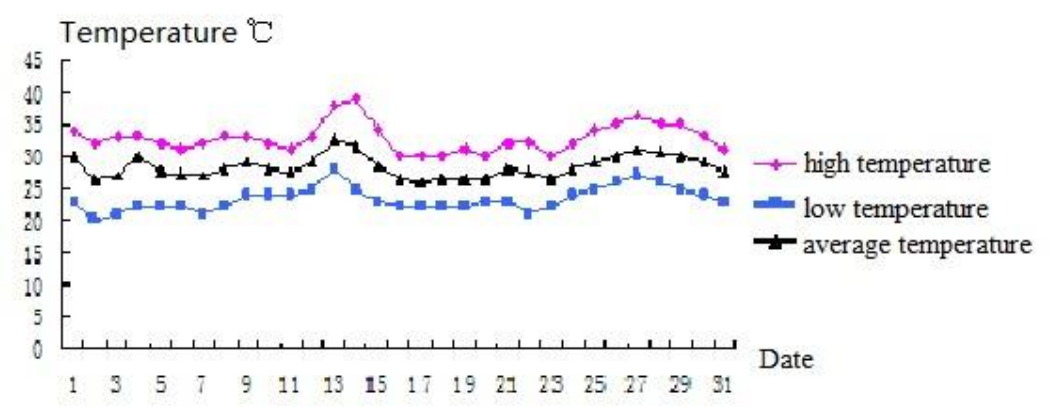

Fig. 2. The temperature change of Jinan in July

The high and low temperature of July 2015 in Jinan ranged from $20^{\circ} \mathrm{C}$ to $39^{\circ} \mathrm{C}$.Daily average temperature ranged from $26^{\circ} \mathrm{C}$ to $32.5^{\circ} \mathrm{C}$ and the average daily temperature difference was $6.5^{\circ} \mathrm{C}$. Overall, except two days' temperature in the middle of this month was much higher than the other days, the average daily temperature in the rest of time was stable. The high temperature of 14th reached the highest temperature of $39^{\circ} \mathrm{C}$, low temperature of $2 \mathrm{nd}$ of this month reached the lowest temperature of $20^{\circ} \mathrm{C}$. The daily average temperature change ranged from $26.5^{\circ} \mathrm{C}$ to $30^{\circ} \mathrm{C}$ in mid-day. Mid-day average temperature ranged from $26^{\circ} \mathrm{C}$ to $32.5^{\circ} \mathrm{C}$, reaching the maximum daily temperature variation. Late average daily temperature ranged from $26.5^{\circ} \mathrm{C}$ to $31^{\circ} \mathrm{C}$.

The Temporal Inhomogeneity of Air Temperature in August. According to Fig. 3,this paper observes the change of temperature in August, 2015 from the three periods of early, middle and late. 


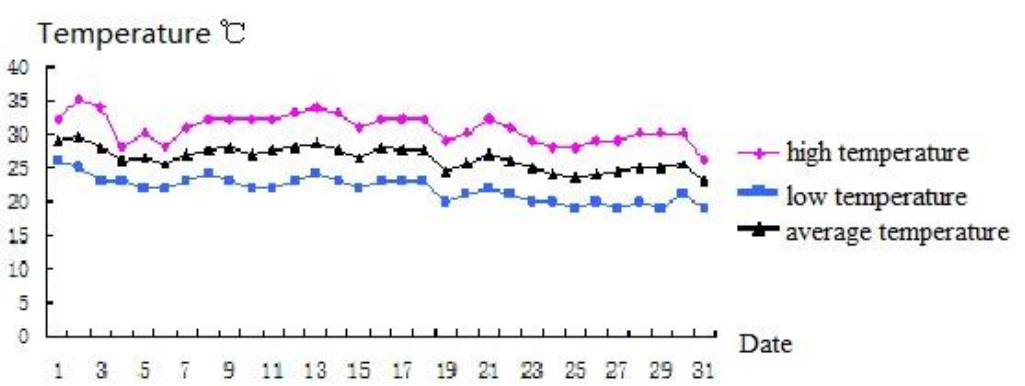

Figure 3. The temperature change of Jinan in August

The high and low temperature of August, 2015 in Jinan ranged from $19^{\circ} \mathrm{C}$ to $35^{\circ} \mathrm{C}$.Daily average temperature ranged from $23^{\circ} \mathrm{C}$ to $29.5^{\circ} \mathrm{C}$ and the average daily temperature difference was $6.5^{\circ} \mathrm{C}$. From the overall point of view, the temperature changes showed a downward trend. The high temperature of 2 nd reached the highest temperature of $35^{\circ} \mathrm{C}$, low temperature of 25 th of this month reached the lowest temperature of $19^{\circ} \mathrm{C}$. The daily average temperature change ranged from $25.5^{\circ} \mathrm{C}$ to $29.5^{\circ} \mathrm{C}$ in early-day. Mid-day average temperature ranged from $24.5^{\circ} \mathrm{C}$ to $28.5^{\circ} \mathrm{C}$. Late average daily temperature ranged from $23^{\circ} \mathrm{C}$ to $27^{\circ} \mathrm{C}$. The average daily temperature change in three periods were $4^{\circ} \mathrm{C}$, indicating that the temperature of August was on a steady decline.

The Temporal Inhomogeneity of Air Temperature in Three Months. Fig. 4 is the summer temperature change trend chart of Jinan in 2015. The figure is made based on June, July and August average daily temperature data. The fluctuation range of the temperature line of Jinan in June 2015 was large and the temperature changed obviously, and the overall trend was descending. According to Gao Weidong, et al 'Jinan City, 1961 to 2000, summer precipitation and temperature trends analysis', it points out: In the past 40 years, the trend of temperature in June has been declining. The temperature dropped in the 1960s and 1970s is the most obvious, and the temperature has risen in recent ten years, and the average temperature was below $27^{\circ} \mathrm{C}{ }^{[6]}$. The average temperature in June of 2015 was $26.5^{\circ} \mathrm{C}$ without mutation.

The air temperature variation of August was the smallest in three months of summer in Jinan 2015. The temperature change was steady and the overall trend was downward. The average temperature in August was $26.5^{\circ} \mathrm{C}$, which was close to the average temperature of $27^{\circ} \mathrm{C}$ in August in Jinan in nearly 40 years ${ }^{[6]}$.

According to Gao Weidong ${ }^{[6]}$, the fluctuation range of temperature line in Jinan in July of 2015 is in the middle place except temperature of 12th and 13th, and the temperature of the remaining time is small. The whole trend is stable, and the average daily temperature is mostly higher than June and August. According to Gao Weidong and other research, the trend of temperature of Jinan in July in the past 40 years is that the temperature showed a downward trend in the 1960s to1980s years, and the temperature has gone up in the 1980s to 1990s. The most significant rise appeared in the late 1980 s to early 1990 s. The July average temperature is $28^{\circ} \mathrm{C}$. . The average temperature is $28.5^{\circ} \mathrm{C}$ on July; 2015.It had no mutation, although it is the highest temperature month among three months.

The average temperature in June, July and August in the whole summer of 2015 is $27.2^{\circ} \mathrm{C}$. There is no abnormality compared with Gao Weidong's research on 'summer temperature of Jinan near $27^{\circ} \mathrm{C}$ in about 40 years'. These results are consistent with the results of Hu Gang, etc. ${ }^{[7]}$. That the summer temperature changes in Jinan from 1951 to 2007 in 55 years are similar to that in Jinan. The results show that the summer temperature in Jinan has no obvious trend of warming with time. 


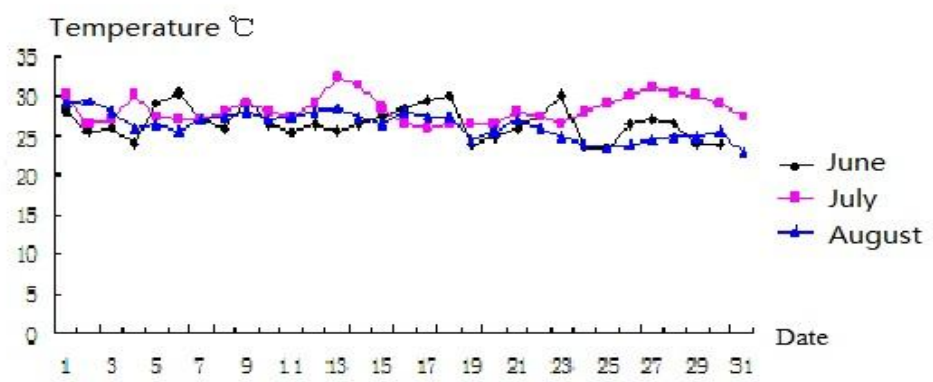

Figure 4. The summer temperature change of Jinan in 2015

Daily Temperature Range. Based on the difference between the daily high temperature and the daily low temperature, we obtain the data of daily temperature range and make Fig. 5.

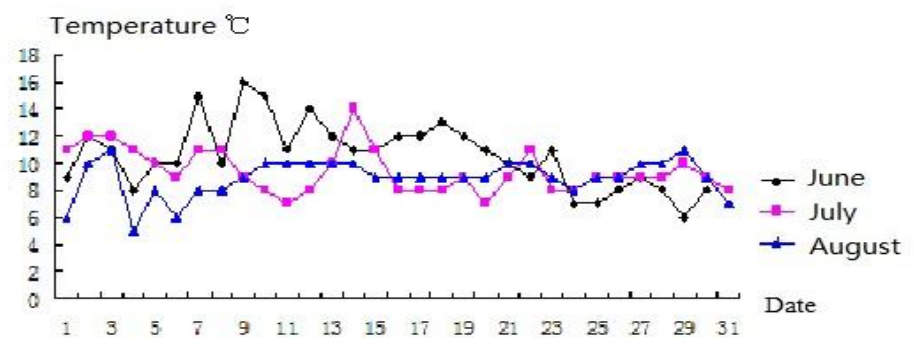

Figure 5. The summer daily temperature range of Jinan

According to Fig. 5, we can conclude that the maximum daily temperature range in summer of 2015 was $16^{\circ} \mathrm{C}$ on June 9th, the minimum was $5^{\circ} \mathrm{C}$ on August 4 in Jinan. The difference of daily temperature range was the biggest in June, followed by July. The August was the smallest. The average daily range was $9.7^{\circ} \mathrm{C}$ in summer, which was higher than the average daily temperature of July and August and was lower than the average daily temperature range in June.

\section{The Spatial Inhomogeneity of Air Temperature}

In order to better distinguish the difference between urban and suburban air temperature, the Tianqiao area, Huaiyin District, Lixia District, Licheng District and the Central District are classified as urban areas with a large population density, industrial concentration, and traffic congestion. The urban areas are mainly use as residential areas, traffic land, urban construction land and give priority to non-agricultural production. The suburbs include Shanghe County, Jiyang County, Zhangqiu City, Changqing District and Pingyin County. The suburbs are densely populated, with concentrated agricultural areas, sparse traffic routes and small proportion of roads. The land use is mainly agricultural Land and are covered by vegetation.

Spatial Difference in Three-month Temperature of Summer. Based on the summer average monthly temperature in Jinan in 2015, we have produced Fig. 6, Table. 1.

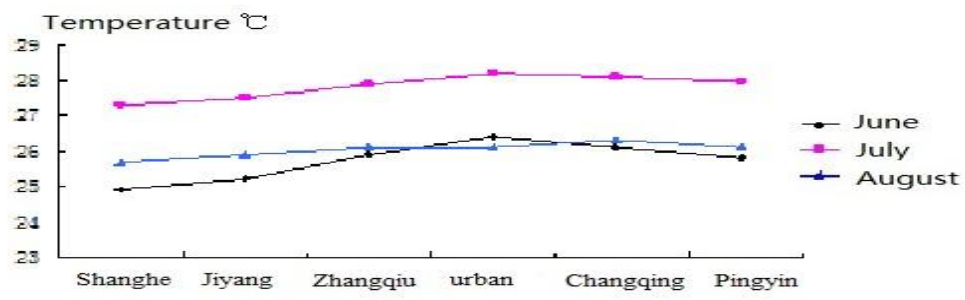

Figure 6. Summer average monthly temperature in Jinan 
Table 1 Summer average monthly temperature in Jinan

\begin{tabular}{|c|c|c|c|c|}
\hline area & $\begin{array}{c}\text { The mean } \\
\text { temperature of Jun. }\end{array}$ & $\begin{array}{c}\text { The mean } \\
\text { temperature of } \\
\text { Jul. }\end{array}$ & $\begin{array}{c}\text { The mean } \\
\text { temperature of } \\
\text { Aug. }\end{array}$ & $\begin{array}{c}\text { average } \\
\text { value }\end{array}$ \\
\hline urban district & $26.4^{\circ} \mathrm{C}$ & $28.2^{\circ} \mathrm{C}$ & $26.1^{\circ} \mathrm{C}$ & $26.9^{\circ} \mathrm{C}$ \\
\hline Shanghe County & $24.9^{\circ} \mathrm{C}$ & $27.3^{\circ} \mathrm{C}$ & $25.7^{\circ} \mathrm{C}$ & $26.0^{\circ} \mathrm{C}$ \\
\hline Jiyang County & $25.2^{\circ} \mathrm{C}$ & $27.5^{\circ} \mathrm{C}$ & $25.9^{\circ} \mathrm{C}$ & $26.2^{\circ} \mathrm{C}$ \\
\hline Zhangqiu City & $25.9^{\circ} \mathrm{C}$ & $27.9^{\circ} \mathrm{C}$ & $26.1^{\circ} \mathrm{C}$ & $26.6^{\circ} \mathrm{C}$ \\
\hline Changqing District & $26.1^{\circ} \mathrm{C}$ & $28.1^{\circ} \mathrm{C}$ & $26.3^{\circ} \mathrm{C}$ & $26.8^{\circ} \mathrm{C}$ \\
\hline Pingyin County & $25.8^{\circ} \mathrm{C}$ & $28^{\circ} \mathrm{C}$ & $26.1^{\circ} \mathrm{C}$ & $26.6^{\circ} \mathrm{C}$ \\
\hline
\end{tabular}

According to Fig. 6, the average temperature in June was the lowest in Shanghe County, followed by Jiyang County, Pingyin County, Zhangqiu City, Changqing District, The highest is urban areas and the difference between high and low temperature is $1.5^{\circ} \mathrm{C}$; the Average temperature in July, the lowest is Shanghe County, followed by other areas of Jiyang County, Zhangqiu City, Pingyin County. The Changqing District is the highest urban, high and low temperature difference of $0.9^{\circ} \mathrm{C}$; Changqing has the highest average temperature in August, followed by Zhangqiu City, urban, Pingyin County which temperature are $26.1^{\circ} \mathrm{C}$. Jiyang County is on the third place. Shanghe County is the lowest with high and low temperature difference of $0.6^{\circ} \mathrm{C}$. The minimum monthly average temperature difference in three months is August, and the largest month is June.

Table 1 shows that the average temperature of Shanghe in summer is $26^{\circ} \mathrm{C}$ which is the lowest value in the six areas. Next is Jiyang County, the average temperature in summer is $26.2^{\circ} \mathrm{C}$. The average temperature of Jinan in summer is $26.9^{\circ} \mathrm{C}$ which is the highest value in the 6 areas; the second high value is Changqing District of which the average temperature of summer is $26.8^{\circ} \mathrm{C}$. The difference between the highest average temperature and the lowest average temperature is $0.9^{\circ} \mathrm{C}$. Shanghe County, Jiyang County, Zhangqiu City, Changqing District, and Pingyin County have the lowest summer average temperature in June Next is August. July is the highest in summer. The lowest monthly average temperature appear in August. Next is June. July is the highest

Daily Temperature Range in Space. Fig. 7 is monthly average diurnal change of Jinan areas trend chart .From the chart, we can see average diurnal variation of June, July and August.

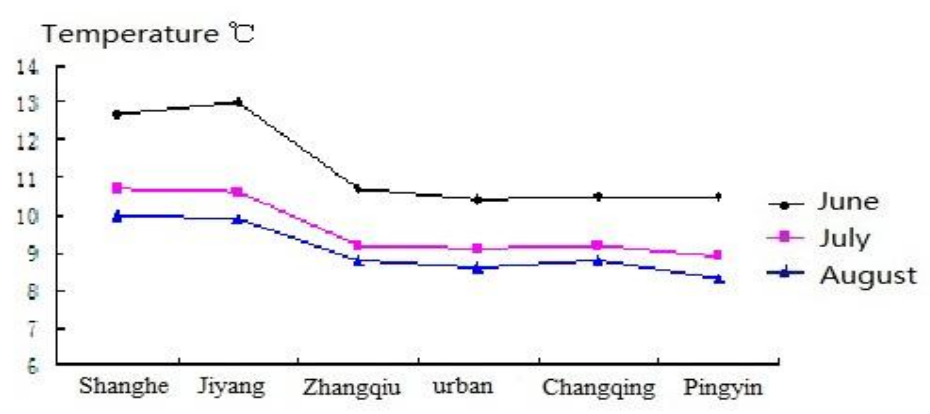

Figure 7. Monthly average daily temperature range in Jinan

According to Fig. 7, we can see that the maximum daily temperature range of Jinan areas appears in June and the minimum appears in August.

Regional Difference Analysis of Summer Extreme Daily temperature range in Jinan. The maximum daily temperature range in summer appeared in Jiyang County, and the maximum daily temperature range was $19^{\circ} \mathrm{C}$ on June 11 th, 2015 . The minimum daily temperature range appeared in Pingyin, Zhangqiu, Changqing District, urban and the minimum daily temperature range is $5^{\circ} \mathrm{C}$ on August 4th, 2015.The difference between the maximum and minimum values of summer daily temperature range in 2015 is $14^{\circ} \mathrm{C}$. Regional differences are very obvious.

Analysis of Regional Differences of Average Daily Disparities in the Same Month in summer. 
The highest average daily temperature range in June was $13^{\circ} \mathrm{C}$ in Jiyang County. The other regions were Shanghe County $12.7^{\circ} \mathrm{C}$, Zhangqiu City $10.7^{\circ} \mathrm{C}$, Changqing District $10.5^{\circ} \mathrm{C}$, Pingyin $10.5^{\circ} \mathrm{C}$ and urban $10.4^{\circ} \mathrm{C}$; the highest average daily temperature range in July was 10.7 in Shanghe County. The other temperature values were $10.6^{\circ} \mathrm{C}$ in Jiyang County, $9.2^{\circ} \mathrm{C}$ in Zhangqiu City, $9.2^{\circ} \mathrm{C}$ in Changqing District, $9.1{ }^{\circ} \mathrm{C}$ in urban area and $8.9^{\circ} \mathrm{C}$ in Pingyin County; The highest average daily temperature range in August was $10^{\circ} \mathrm{C}$ in Shanghe County, and the other areas' temperature values were $9.9^{\circ} \mathrm{C}$ in Jiyang, $8.8^{\circ} \mathrm{C}$ in Zhangqiu, $8.8^{\circ} \mathrm{C}$ in Changqing, $8.6^{\circ} \mathrm{C}$ in urban area and $8.3^{\circ} \mathrm{C}$ in Pingyin.

Table 2 Comparison of spatial difference of daily temperature difference

\begin{tabular}{ccccccc}
\hline area & time & Max. value & time & Min. value & max.-min. & Location in the city \\
\hline urban district & June. 9th & $16^{\circ} \mathrm{C}$ & Aug. 1st, 4th & $5{ }^{\circ} \mathrm{C}$ & $11^{\circ} \mathrm{C}$ & Middle \\
Shanghe County & Jun. 10th & $18^{\circ} \mathrm{C}$ & Aug. 4th & $6^{\circ} \mathrm{C}$ & $12^{\circ} \mathrm{C}$ & North \\
Jiyang County & Jun. 11th & $19^{\circ} \mathrm{C}$ & Aug. 4th & $6^{\circ} \mathrm{C}$ & $13^{\circ} \mathrm{C}$ & North \\
Zhangqiu City & Jun. 10th & $16^{\circ} \mathrm{C}$ & Aug. 4th & $5{ }^{\circ} \mathrm{C}$ & $11^{\circ} \mathrm{C}$ & East \\
Changqing District & Jun. 10th & $15^{\circ} \mathrm{C}$ & Aug. 4th & $5^{\circ} \mathrm{C}$ & $10^{\circ} \mathrm{C}$ & West \\
Pingyin County & Jun. 10th & $15^{\circ} \mathrm{C}$ & Aug. 4th,31st & $5^{\circ} \mathrm{C}$ & $10^{\circ} \mathrm{C}$ & Southwest \\
\hline
\end{tabular}

As can be seen from Table 2, the amplitude of variation of extreme daily temperature range in Jinan is gradually decreasing from north to South and from east to West. The monthly average daily temperature range in Jiyang County was the largest among the counties in Jinan. Next are Shanghe County, Pingyin County, Zhangqiu City and urban area. Changqing City's monthly average daily temperature range is the smallest, in Jinan. The monthly average daily difference of Jiyang is the biggest difference, and the other areas are Shanghe County, Pingyin County, Zhangqiu City, urban area, and the average monthly daily life is the smallest. The monthly average daily temperature range of Jiyang county is the biggest, which is $11.2^{\circ} \mathrm{C}$, the other areas' daily temperature range are $11.1^{\circ} \mathrm{C}$ in Shanghe County, $9.6^{\circ} \mathrm{C}$ in zhangqiu city, $9.5^{\circ} \mathrm{C}$ in changqing, $9.4^{\circ} \mathrm{C}$ in urban district, $9.2^{\circ} \mathrm{C}$ in pingyin county. This law basically continued the trend of extreme temperature diurnal variation range from north to South and from east to west. This trend indicates that the diurnal variation of summer air temperature is mainly affected by topography and latitude.

\section{The Causes of Spatiotemporal Inhomogeneity Characteristics of Air Temperature}

Yu Qun, who comes from Ocean University of China, his article called "Shandong Province in summer and winter temperature variation of climate characteristics and interannual variation analysis "pointed out that summer temperature factor is more complex than winter. Jinan city is located in north latitude 36 degrees 40', 117 degrees east longitude 00', South in Taishan, north across the Yellow River and is located in the Middle South Hilly and northwest alluvial plain transition zone. The layout of Jinan declines from north to south and the city is dominated by plains, hills and mountains, belonging to warm temperate semi humid monsoon climate. It has four distinctive seasons and the average annual temperature is $13.8^{\circ} \mathrm{C}$.The topography and latitude distribution of Jinan make the temperature change more complicated.

Jinan is located in the eastern part of China, which is characterized by the warm temperate monsoon climate region, so the characteristics of continental temperature are obvious. So the average temperature in summer in Jinan is the highest in July, and the average temperature in June and August are lower.

Because of the unique characteristics of warm temperate monsoon climate, summer precipitation in Jinan city is the most, especially concentrated in July and August. In sunny weather, solar radiation and the ground temperature are strong during the day. Ground effective radiation and cooling are strong at night. Therefore, the daily temperature range of the sunny day is much higher than that of the rainy day. And because every year after June 22nd, Jinan city is the highest altitude of the sun during the day time, but at night the height of the sun throughout the year are zero, so the 
summer in Jinan is the season which has the maximum daily temperature range caused by the height difference of the sun. Therefore, the maximum daily temperature range of Jinan in summer often appears in June. The maximum daily temperature range is $16^{\circ} \mathrm{C}$ appeared in June 9th, 2015. The maximum daily temperature range of Jinan occurred in June and the minimum appeared in August.

The latitude and longitude of each county in Jinan is gradually reduced from north to south. The latitude of Shanghe County is the highest, so the average temperature of June, July and August in Shanghe is the lowest.

The urban population density is higher than the surrounding areas. Human activities, city heat release and activity intensity are higher than the surrounding areas. Hardened ground is more than the suburbs. So urban temperature is higher than the surrounding area, this is what we usually say the heat island effect [10-14]. So Jinan become the area with the average maximum temperature in June and July. The average temperature of 2015 in summer is $26.9^{\circ} \mathrm{C}$ which is the highest value among the six regions (see Table 1). Because the heat island appears during the day and the wet Island often appears at night, the night temperature drops slowly and the urban daily temperature range is less than the suburbs.

The reason for selecting summer temperature variation of Jinan in 2015 to conduct research in this paper is to further explore the impact of El Nino on summer temperature of Jinan in June, July and August,2015. However, through the analysis of the data, it is found that the average temperature of Jinan is $28.5^{\circ} \mathrm{C}$ in July, 2015 and the average temperature are $26.5^{\circ} \mathrm{C}$ in June and July. This result is similar to the summer temperature change in Jinan in 1961-2000 which was studied by Gao Weidong, et al and in 1951-2007 which was studied by Hu Gang, et al. This shows that El Nino has little effect on temperature change.

\section{Acknowledgements}

This paper is derived from the social science fund of University of Jinan: X1146.

\section{References}

[1] Liner Ji, Shuqing Sun. Observational and Model on Interpersonal Connection of Atmospheric Circulation, General Circulation of the Atmosphere [M]. Beijing: China Meteorological Press, 1995

[2] Guifang Hu, Deqiang Xue, Xiufen Xi. The Air Temperature Change of the last Hundred Years in Shandong [J]. Journal of Shandong Meteorology, 2003, 23(3): 8-11

[3] Xian Sun, Zhenshan Lin, Xiaoxia Cheng, et al. JIANG Chuangye1Regional Features of the Temperature Trend in China Based on Empirical Mode Decomposition[J]. Journal of Geographical Sciences, 2008, 18:166-176

[4] Xin Zhou. Analysis on Interannual and Interdecadal Variability of Temperature over China and its Simulation [D]. Nanjing University of Information Science \& Technology, 2013

[5] Liangyu Zhang, Xiaobo Lu, LiliYang, et al. Study on the Effects of the Strong El Nino Event on Air Quality of the Eastern China in Winter[J]. DOI:10.19501/j.cnki.1006-2009.20161107.001. http://www.cnki.net/kcms/detail/32.1418.X.20161107.0947.002.html

[6] Weidong Gao, Naijin Duan. Analysis on Summer Temperature and Precipitation Change Trend of Jinan between 1961 and 2000 [J]. Journal of University of Jinan, 2008, 22(3):280-287

[7] Ganga Hu, Hui Song. Analysis of Air-Temperature Variation Trend and Abrupt Change in Jinan Based on Mann-Kendall Test [J]. Journal of University of Jinan, 2012, 26(1):96-101

[8] C1imate Characteristics of Summer and Winter Temperature and Interannua1 Variation Analysis in Shandong Province [D]. Ocean University of China, 2010 
[9] Hongwei Xu. Quantitative Monitoring and Driving Factor Analysis of Urban Heat Island Dynamic Change in Jinan City using MODIS LST[J]. Environmental Science and Management, 2014, 39(10):80-85

[10] Shuqing Zhao, Decheng Zhou, Shuguang Liu. Data Concurrency is Required for Estimating Urban Heat Island Intensity [J].Environmental Pollution. 2016, 208:118-124

[11]Decheng Zhou, Liangxia Zhang, Lu Hao, et al. Spatiotemporal Trends of Urban Heat Island Effect Along the Urban Development Intensity Gradient in China [J]. Science of the Total Environment .2016, 544:617-626

[12] Tong Sun; Minhua Zhao; Rongqing Han, et al. Strategy of Adaptation to Extreme High Temperature in Summer of Ji'nan City under Urban Expansion and Urban Heat Island Effect [J]. Modern Urban Research, 2014, (4):67-72

[13] Guiping Ran, Rui Li, Dan Ren, et al. The Temporal and Spatial Distributions of Urban Heat Island Effect in Jinan City [J]. Western Resources, 2011, (6):92-94

[14] Tongguang Shi, Lijuan Wang, Fei Meng. Study on Heat Island Inversion of Jinan City Based on Remote Sensing [J]. Journal of Shandong Jianzhu University, 2008, 23(6):482-485 